\title{
Discussion on Sketch Teaching
}

\author{
Qunying Li \\ Department of Art Design \\ Shan Dong Vocational College of Light Industry \\ Zibo 255300, China \\ e-mail: liqunying2000@126.com
}

\begin{abstract}
As a basis of plastic arts foundation, teaching of sketch basis is developed following the creation principle of realism, and is rooted in the prototype of traditional figurative realism. It enables the exploration, research and teaching for the rule of modeling and form. As the gateway for sketching, therefore, teachers are guiding the students to study on objective things. In the teaching of stationary objects sketching, the author of this thesis classified linear structure sketching, tone sketching, multiple comparison and manifestation as the teaching units, and unfold the teaching respectively. Teachers should also pay attention to exploring and researching the scientific teaching methods, properly using modern teaching technique to an individualized education and teach students according to their aptitude.
\end{abstract}

Keywords- elementary sketch teaching; stationary objects sketching teaching; design sketch; creative thinking; teaching units

\section{INTRODUCTION}

As a basis of plastic arts foundation, teaching of sketch basis is developed following the creation principle of realism, and is rooted in the prototype of traditional figurative realism [1-4]. It enables the exploration, research and teaching for the rule of modeling and form. As the gateway for sketching, therefore, teachers are guiding the students to study on objective things. In the teaching of stationary objects sketching, for example, geometric figure work is the beginning of sketch learning [5-7]. It enables the students to learn the volume, structure and space perspective principle of the geometric figure, as well as its universal meanings reflected on other objects, leading the students to transit from imitation to the thinking and mastery of modeling language. In the teaching of stationary objects sketching, I often classify the linear structure sketching, tone sketching, multiple comparison and manifestions as the teaching units, and unfold the teaching respectively [8-10].

\section{LINEAR STRUCTURE SKETCHING}

Wherever To observe and express the objective natural images structure and characteristics through the line. By rational analysis of the images inner structure, it could help to form a deep understanding towards the images, and then could comprehend the skeletal structure and space composition from body structure, and refine the aesthetic form of the line itself. The teaching of linear structure sketching focuses on the grasp of three aspects, which are the laws of visual perspective, reasonable structural analysis and the ordinal organization of the pictures.

\section{A. Mastery of the laws of visual perspective}

First, the main point is to make students understand the basic laws of parallel perspective (one-point perspective) and angular perspective (two-point perspective), and gather it through the repeat imitation of gypsum geometry. To clearly grasp the perspective of the objects and accurately control the angle and proportion, teachers should also draw the invisible parts (virtual solid) to allow the students to know that the cylinders and cones are varied from the "cutting" of the cuboids.

\section{B. Reasonable structural analysis}

Structure forms the connection and combination of various shapes. The physical structure is divided into two types: matrix type and volume type. During the sketch study, teachers should lead the students to perceive it through physical structure, to master it through construction, and essentially grasp the inherent law and varying pattern, thus having a good command of profundity of the sketch expression.

\section{Ordinal organization of the pictures}

It means constituent elements of the picture, "to express the nature through cylinders, spheres and cones, putting everything into the perspective“. In the view of Cezanne, the ordinal organization of drawing form should be found through geometrical forms under the law of nature, which means to observe and understand the objective natural world as a whole with the inductive method. In the teaching of stationary objects sketching, teachers should follow this method to ask students to subjectively make the meaningful trade-offs of the grain line among a point, a single line, a surface, the composite relation between objects, the survival relationship of the objects and background. Therefore, the picture will be formed as an ordered whole. Units

\section{TONAL SKETCHING}

To achieve natural lighting and a three-dimensional visual effect, the three colored sides and five shading tones of the objective things should be generalized and exhibited by means of light and shade. It is often referred to as allfactor sketching. In the training of the tone sketching, teachers should enhance students ${ }^{6}$ awareness of lighting, as well as black and white. It will allow students to focus on the tonal variation rhythm of light and shade, raising the three-dimensional concept and space consciousness. 


\section{A. The awareness of lighting as well as black and white}

It is an important factor to form a complete visual expression that lighting creates light and shade, which in turn make black and white. Lighting is the foremost marker in our perceptual space, while light and shade reflect the shape structure of the objects under the light exposure. The essential structure of an object determines its light intensity value, while its shape and essential structure remain the same wherever the light is. Given that the light and shade create black and white, teachers should lead the students to notice the positive and negative space between objects and backgrounds, as well as the picture's constitutive relationship between black and white formed by the light and shade of the objects. Among which, the development of the consciousness on the focus on black and white center, the contrast and rhythm, division and cohesion, the layout of black, white and grey, and the black and white tone are especially important.

\section{B. The tonal variation rhythm of light and shade}

The overall observation and expression should run through the drawing from beginning to end. In the teaching process of deepening the light and shade, teachers should make the students realize the rhythmical principle of gradual change created by people's visual sense between the lights, the shades and the intermediate colors. Generally speaking, the object owns only one brightest part and one darkest part; other parts are less brighter, and more less brighter... in descending order, thus producing a regular changing law of colouring tone.

\section{Three-dimensional concept and space consciousness}

One of the pursuing goals of the entire sketching training process is the sense of volume and space, which is also the direct embodiment of the sketching concept. Overall volume is as necessary as the detailed volume. Prior to the drawing, one should first analyze the relationship of form and object, and focuses on the object's structural line and turning point; secondly, one should keep an eye on the surface rolling of the objects, which has a direct relationship with the change on the shape and the meeting-line of the light and shade. The meaning of the overall volume lies in the following of the perspective laws and submitted to the whole picture.

\section{MULTIPLE COMPARISON AND MANIFESTATION}

Specifically, it means the observations and manifestations of various comparison relations created in the specific environment by the material qualities, modelings and colorities of the object itself. In the practice of the mutiple comparison, teachers should unfold and implement the teaching through three points, which are quality manifestations, comparison consciousness and aesthetic treatment.

\section{A. Quality manifestations}

The importance of physical appearence formed by the object's material quality is in its grain and weaves. It will form various visual perceptions such as smooth or rough, tough or soft, dry or moist from the sense of vision and touch, taking the products like glasswork, metalware, wood, fur and feather, crude pottery as well as flowers and plants as the examples. How to express the inner feelings of the viewers? One should observe the rules of the object's texture: it is disorganized, rude or exquisite? This is the manifestation breakthrough. To simulate the texture quality through the ordered linear arrangement, or rubbing, smudging, dotting and scraping, thus reaching the true visual feelings.

\section{B. Comparison consciousness}

The degree of thickness, length, twists and turns of the lines; the size, the square and round, positive and negative of the graphs; the black and white, strong and weak of the light and shade; the coldness and warmth, red and green of the color; the toughness and softness, smoothness and roughness, dryness and moistness of the materials, all these can produce the contrast of the two opposing extremes. Comparison creates contrast, which in turn invokes visual stimulation. In the training of stationary objects sketching, the application of comparison and contrast can acquire a lively and vivid, rich and intense visual effects and aesthetic feelings.

\section{Aesthetic treatment}

Imaginal thinking principles are being employed to observe and discover beauty, and find the artistic factors with aesthetic values throughout the entire sketching process. In the teaching, teachers should lead the students to lift the recognition of the images towards the height of an art-form beauty to observe, and to discover the feelings of formal aesthetics, dynamics, profoundness, rhythm and order, actively applying modeling elements like dot, line, plane, black, white and gray to express the objects and feelings.

\section{V.CONCLUSIONS}

In the course of teaching, teachers should bring the predominant role of the instruction into full play, making the targeted training through the form of teaching units. Teachers should also pay attention to exploring and researching the scientific teaching methods, properly using modern teaching technique to an individualized education and teach students according to their aptitude.

\section{ACKNOWLEDGMENT}

The authors would like thank the 2015 Annual Vocational Education Reform Projects of Shandong Province (No. 2015040) for financial support.

\section{REFERENCES}

[1] A. D. Li. "Sketch basic teaching in art design education", Journal of Nanjing Institute of Industry Technology, vol. 2, Mar. 2005, pp. 34-36, doi: 10.15903/j.cnki.jniit.2002.03.009.

[2] D. H. Yi and W. Liu. "Dialogue on the teaching of sketch basic", Journal of Linyi University, vol. 2, Apr. 2015, pp. 97-101, doi: 10.13950/j.cnki.jlu.2015.02.021.

[3] Q. Ying. "On the teaching innovation of the sketch foundation course in design speciality", China Packaging Industry, vol. 24, Dec. 2014, pp. 153-154, doi: 10.14047/j.cnki.cpi.2014.24.105.

[4] J. L. Guo and N. Zuo. "Talk about the basic sketch of meticulous figure paintings", Journal of Mudanjiang Teachers University(Philosophy Social Sciences Edition), vol. 5, Oct. 2009, pp. 110-111, doi: 10.13815/j.cnki.jmtc(pss).2009.05.033.

[5] X. H. Zhu. "The exploration of the teaching mode of the sketch foundation platform for the art design specialty", Big stage, vol. 11, Nov. 2012, pp. 245-246, doi: 10.15947/j.cnki.dwt.2012.11.026. 
[6] Z. X. Wang. "Reform of design sketch teaching", Art Research, vol. 2, May. 2006, pp. 63-64, doi: 10.13944/j.cnki.ysyj.2006.02.031.

[7] C. H. Ding and Q. S. Li. "Using the structure sketch teaching reform of Sketch Teaching", Education and Vocation, vol. 2, Jan. 2007, pp. 151-152, doi: 10.13615/j.cnki.1004-3985.2007.02.006.

[8] C. C. Cui. "A new idea of applying performance sketch in the design of professional Sketch Teaching", Education and Vocation, vol. 3, Jan. 2013, pp. 142-143, doi: 10.13615/j.cnki.10043985.2013.03.015.
[9] Y. F. Liu. "Teaching reform and Exploration on the teaching reform of the design sketch course for the university art design", Modern Education Science, vol. 11, Nov. 2011, pp. 154-155, doi: 10.13980/j.cnki.xdjykx.gjyj.2011.11.007.

[10] Z. J. Wu. "Reform and practice of the teaching reform and practice of the design and drawing of the engineering industry design specialty in Colleges and Universities", Education and Vocation, vol. 33, Nov. 2013, pp. 134-135, doi: 10.13615/j.cnki.10043985.2013.33.0. 